\title{
El guarango en el cantón guano de la provincia de Chimborazo - Ecuador
}

\section{RESUMEN}

En los últimos años ha habido una creciente producción del Guarango producto nativo de la zona, pero no existe un medio para realizar la comercialización de los productos y subproductos que se puede sacar de este producto. Al mercado mundial y explotar todos los beneficios que este pudiera tener.

Palabras clave: Comercialización, modelo de gestión, industrialización, guarango.

THE GUARANGO IN THE GUANO CANTON OF THE PROVINCE OF CHIMBORAZO - ECUAdOR

\section{ABSTRACT}

In recent years there has been a growing production of Guarango native product of the area, but there is no means to carry out the marketing of products and by-products that can be derived from this product. To the world market and exploit all the benefits that this could have.

Keywords: Marketing, management model, industrialization, guarango.

\section{INTRODUCCIÓN}

Guano es un cantón de la provincia de Chimborazo en el Ecuador, cuenta con una superficie de $473 \mathrm{~km}^{2}$ es un importante centro artesanal de tejidos de lana, su especialidad es la elaboración de alfombras y artículos de cuero. La pobreza por necesidades básicas insatisfechas alcanza el $83.44 \%$ de la población total del cantón y la extrema pobreza es del $49.6 \%$, según datos del último censo del 2010 realizado por el INEC su población es de 42,851 habitantes en la zona urbana y 7,758 habitantes en la zona rural.

Guano cuenta con 31,822 ha. De los cuales en el uso de suelo según el censo agropecuario realizado por el INEC en el año 2000 solo 339 ha son ocupadas por cultivos permanentes que representa el $1.07 \%, 13,611$ ha en cultivos transitorios que representa el $42.77 \%, 3071$ hectáreas (ha) en suelo de descanso que representa el $9.65 \%, 5,462$ ha en pastos cultivados que es el $17.16 \%, 1,532$ ha en pastos naturales que son $4.81 \%, 4,394$ ha en paramos que representa el $13.81 \%, 2,917$ ha en montes y bosques que son el $9.17 \%$ y en otros usos solo 496 ha que representa el $1.56 \%$ del total de la hectáreas que tiene el cantón.

El Guarango, Campeche, Vainillo, Espino, Tara o Taya cuyo nombre científico es Caesalpinia spinosa, es un arbusto que se adapta bien a condiciones semiáridas, a suelos degradados y a terrenos laderosos, necesita de pocos cuidados se extiende por todos los Andes, desde Venezuela hasta Chile, crece desde los 50 hasta los $2,800 \mathrm{msnm}$.

En el Ecuador se le conoce como Guarango principalmente se lo encuentra en la región de la Sierra y crece en zonas áridas y semiáridas es una especie relegada sistemáticamente que ha estado a punto de desaparecer por el desconocimiento de las bondades y la introducción de cultivos y especies maderables, ha sido utilizada desde la época prehispánica para la elaboración de tintes, el curtido de pieles e incluso en la medicina popular (Mancero, 2008)

Es una planta utilizada desde la época de los Incas en la tintorería, curtiembre de cueros, pero también en la medicina tradicional como astringente, cicatrizante, antidisentérico y en especial

Docente de la Escuela Superior Politécnica del Chimborazo, Doctor en Gestión de Empresas. E-mail: stalin.arguello@espoch.edu.ec

2 Docente de la Universidad Nacional de Chimborazo, Master en Finanzas. E-mail: wilosaltos@unach.edu.ec 
contra la amigdalitis en forma de gárgaras De la Cruz (2004). Sus pepas eran utilizadas para impermeabilizar los pondos de la chicha que es una bebida tradicional y originaria de los andes, frotando estos con una goma que se produce en las mismas pepas, la industrialización del Guarango influyó para que estas costumbres queden en el olvido.

El tiempo de cosecha es relativamente corto se cultiva de una manera adecuada con riego y fertilización a los 3 años produce la vaina se puede cosechar dos veces al año sin mayor mantenimiento ni inversión. Este árbol tiene una vida útil de hasta 60 años y al ser una leguminosa, aporta nitrógeno al suelo, es un árbol de 2 a 3 metros en ciertos lugares llega hasta los 12 metros si el suelo tiene abundante agua y es rico en nutrientes.

\section{COMERCIALIZACIÓN}

Todo intercambio comercial se ha dado entre las personas desde tiempos antiguos pero su estudio se lo realza a través de la mercadotecnia. La orientación al productor se da antes del año 1900 se vendía lo que el productor deseaba o producía; la orientación hacia las ventas se da a partir del año 1950 el mismo se promueve por la escases de los alimentos la misma que se origina por la venta de la producción. Las dos orientaciones se centran en el producto su venta está en función del incremento de la competencia Kotler \& Armstrong (1994), Malhotra (2004) y Orci (2007)

Las formas de intercambio se han caracterizado por darle una orientación a la producción, al producto o a las ventas según acorde al concepto de comercialización tradicional. (Abbott, 1969). Esto ha cambiado conforme avanza el estudio de la mercadotecnia y sus instrumentos, la tendencia actual es hacia los consumidores los mismos que buscan la satisfacción lo que conlleva que el estudio del mercado sea una tarea más compleja Nicolai (2007).

Para Mesa (2012) la comercialización se relaciona con todas las actividades a desarrollar por parte de los fabricantes e intermediarios para ajustar el producto a las necesidades del mercado. Incluye acciones de precio, distribución, comunicaciones de marketing y servicio posventa.

La comercialización Garnica \& Maubert, (2009) es la etapa que se planea y finalmente se ponen en práctica los programas de producción y marketing a gran escala. Una vez que el producto nace y entra en su ciclo de vida, el ambiente competitivo externo se convierte en el principal determinante de su destino.
Para Kotler \& Armstrong, (2008) la comercialización es la introducción de un nuevo producto al mercado.

Pero la comercialización no solo debe de ser la introducción de nuevos productos sino también son las estrategias para que productos ya existentes se les busque nuevos mercados y obtener una mayor cobertura lo que generará mayor posicionamiento y venta de los productos.

Según Kotler, (1995) el proceso de comercialización incluye cuatro aspectos fundamentales: ¿Cuándo?, ¿Dónde?, ¿A Quién? Y ¿Cómo? En el primero el autor se refiere al momento preciso de llevarlo a efecto; en el segundo, a la estrategia geográfica, y en el tercero, a la definición del público objetivo. Finalmente, hace referencia a la estrategia a seguir para la introducción del producto al mercado, en la llamada Economía de Conocimiento,

Existen pocas aplicaciones de la mercadotécnica enfocadas al medio rural en especial al área de agro negocios Nicolai (2007), su desarrollo y ámbito de aplicación en las acciones comerciales en el medio rural es muy reducido.

Así mismo la comercialización de productos se relaciona con el desarrollo comercial; son todas las actividades de planeación de los fabricantes e intermediarios diseñadas para ajustar el producto a las necesidades del mercado; incluye estrategias de precio, distribución, comunicaciones de marketing y servicios posventa la comercialización es el termino más usado y se puede considerar como un sinónimo de marketing Mesa (2012).

Sin embargo, su valor económico más relevante, está sustentado por el alto contenido de taninos que se obtienen de sus vainas, lo cual le confiere el privilegio de ser un producto de exportación a precios competitivos, que, sin duda alguna, va a beneficiar significativamente en la economía campesina e indirectamente en la economía urbana. Flores \& Chavarry, (2005).

La comercialización del guarango y de sus subproductos, como vaina, semilla y cascara, son una alternativa para contribuir al desarrollo del cantón Guano y sus parroquias tanto rurales como urbanas, estos productos ofrecen ciertas ventajas que podrían ser aprovechadas, en algunas regiones, para afrontar los problemas que aquejan a los sectores de población de escasos recursos económicos, y atender a los centros donde existe la mayor demanda de consumo.

La Comercialización es el principal problema que se enfrenta este cantón ya que no existen organizaciones que fomenten esta actividad productiva, las causas que provocan una ineficiente comercialización son las siguientes: 
- Falta de asesoría a los pequeños productores de guarango para la comercialización de sus productos.

- Escasa tecnología para la producción y mercadeo del guarango y sus subproductos, el descuido de los productores de acudir a instituciones privadas y centro de asesoramiento del gobierno para conocer sobre sistemas de comercialización de los mismos.

- Falta de organizaciones para la comercialización que den un valor agregado, y así obtener mayores ingresos.

- Escasa cultura comercial del guarango, en las zonas rurales, suburbanas y urbanas.

- Los canales de comercialización con poca participación que no agregan ninguna utilidad lo cual ha generado que los precios no estén acordes a la utilidad de quienes participan en ella.

En el Cantón Guano provincia de Chimborazo es necesario implementar programas de cooperación y alianzas estratégicas, con el fin de conformar sistemas comerciales que respondan a las condiciones actuales y futuras, las mismas que garantizan el desarrollo económico del sector y quienes forman parte de esta actividad comercial. El guarango o tara es una opción muy interesante para mejorar los ingresos de los pequeños campesinos del cantón Guano, así ocurre en países vecinos como Perú que han desarrollado esta actividad como fuente de ingreso de igual forma se quiere fomentar en Ecuador para poder mejorar los ingresos y la calidad de vida de los campesinos.

\section{INDUSTRIALIZACIÓN DEL GUARANGO}

El fruto o vaina del guarango presenta dos partes principales que son, la cáscara externa o pericarpio y las semillas. La cáscara del fruto representa aproximadamente el $63 \%$ del peso de los frutos y es la parte que contiene la mayor concentración de taninos.

Entonces, el primer paso del procesamiento del guarango es la trilla, proceso mediante el cual se separa las semillas de las vainas. Tanto las vainas como las semillas se deben almacenar en sacos o pilones, por separado, y en bodegas secas y ventiladas, para conservar las características organolépticas del producto Villanueva (2007).

De la molienda de la cáscara, se obtiene una harina de color amarillo claro, con un contenido aproximado de taninos de 40 a $60 \%$. Esta harina es el primer producto comercial de exportación.
A partir de esta, se puede aumentar el valor agregado del producto, mediante un proceso de concentración de los taninos en forma de Ácidos Tánico o Gálico, que son muy demandados en el mercado internacional, como materia prima para varias industrias, Alnicolsa (2009).

Por su parte, las semillas tienen en su composición porcentual en peso, alrededor del 35\% de tegumento, aproximadamente $24 \%$ de endospermo o goma, y alrededor del $40 \%$ de germen o cotiledones. Los tres subproductos tienen aplicaciones industriales, los cotiledones tienen demanda en el mercado nacional y en el caso de la goma tiene demanda en el mercado internacional.

Se presenta la distribución de productos y subproductos posibles de obtener de la industrialización del guarango, con una aproximación a la valoración en porcentajes de extracción y precios de mercado:

Materia prima (vaina) $1,000 \mathrm{~kg}=\$ 400$

- Polvo $630 \mathrm{~kg}(63 \%)=\$ 630$

- $\quad$ Semillas $350 \mathrm{~kg}(35 \%) .=\$ 280$

- Desperdicios $20 \mathrm{~kg} \mathrm{(2 \% )}$

Semilla

- $\quad$ Goma 84 kg $(24 \%)=\$ 462$

- Cáscara $119 \mathrm{~kg}(34 \%)=\$ 12$

- Desperdicios $7 \mathrm{~kg}(2 \%)$

- Germen $140 \mathrm{~kg}(40 \%)=\$ 70$

\section{USOS Y APLICACIONES}

En primer lugar, hay que resaltar el valor ambiental del guarango. Es una especie nativa muy útil en la protección de suelos que están erosionados o en proceso de erosión. También sirve para barreras vivas, protección de laderas, protección de acequias y cursos de agua, como barreras buffer. Sirve para mejorar el paisaje y la biodiversidad local, al plantarse en asociación con todo tipo de cultivo. La competencia del guarango con las plantas asociadas es casi nula, puesto que su raíz es pivotante y profunda, su copa es poco densa y deja pasar la luz para las especies asociadas. Además, el guarango es una planta melífera.

La madera del guarango sirve para vigas, postes y otros materiales para la construcción de viviendas; para mangos de herramientas y postes para cercas; para leña y carbón, por sus bondades caloríficas.

De los frutos procesados, se obtienen una serie de productos y subproductos, de los cuales, los princi- 
pales son los extractos de taninos, que se obtienen de las cáscaras de las vainas molidas. Los taninos tienen aplicaciones directas en la industria, así: se los usa para el curtido de pieles, clarificación de vinos y de cerveza, fabricación de plásticos y adhesivos, elaboración de productos farmacéuticos, entre otros.

El polvo de guarango utilizado en la curtiembre de cueros, da como resultado un cuero claro, resistente a la descomposición y al ataque bacteriano, impide el encogimiento y la formación de grumos por las fibras de colágeno. Además, mezclado con otros extractos, el polvo es excelente para el curtido de pieles de camello, cabra, reptiles y para el recurtido de toda clase de procesos al cromo; principalmente para tonos claros. Otras áreas de aplicación son la cosmetología, industria del caucho y es componente de pinturas, por su efecto anticorrosivo Cabello (2009)

En medicina popular se usa y recomienda para alivio de malestares de garganta, sinusitis, infecciones vaginales, lavado de ojos inflamados, heridas crónicas y diarreas infecciosas. Además, es considerado como un depurativo del colesterol. Este tema del uso en la medicina tradicional, merece una investigación científica seria, para formalizar o rechazar algunos de los usos propuestos.

Las semillas una vez procesadas dan lugar a por lo menos tres subproductos:

- El tegumento, que puede ser utilizado como componente de balanceados para animales, o para preparar materiales de tipo aglomerado;

- La goma o endospermo, que es un subproducto de aplicación como espesante de alimentos. La goma posee las características propias de las gomas vegetales, actúa como espesante, aglomerante, estabilizador, coloide y capa protectora. Posee la ventaja de ser incolora, insípida, muy estable y altamente resistente a la descomposición, Alnicolsa, (2009).

- $\quad$ El germen o cotiledones, que contiene un alto valor proteínico, (con alto contenido de los aminoácidos Metionina y Triptófano) por lo tanto, sirve para el consumo humano o para la alimentación animal. El germen también contiene aceites con un contenido de ácidos libres de $1.4 \%$ (ácido oleico), que es comercialmente aceptable por su baja acidez, Alnicolsa, (2009).

En farmacéutica, la goma de guarango se usa como un depresor del apetito y como desintegrador y agente aglutinador en tabletas y comprimidos. También se usa para espesar diferentes cosméticos como lociones y cremas. La manufactura de papel es uno de los principales usos de la goma de guarango, en este caso, se la utiliza como agente retenedor de humedad y corrector de irregularidades en las prensas y calandras.

El potencial comercial del guarango está directamente relacionado con la demanda insatisfecha de sus derivados, tanto en el mercado nacional como internacional. La demanda está abierta tanto para polvo o extracto de taninos como para subproductos del mismo como son los ácidos Tánico y Gálico. Pero también la demanda está para los derivados de la semilla, como son: el endospermo (goma) y los cotiledones (germen).

Para estos y otros subproductos del guarango, se requiere satisfacer la demanda, a través de la oferta sostenida en cantidad y con altos estándares de calidad.

Los principales países compradores de polvo o extracto de guarango son: China, Italia, Brasil, Argentina, Holanda, México, Uruguay y Chile; mientras que los destinos principales para la goma de guarango son: Holanda, Francia, España, Alemania, Bélgica, Italia y Rusia.

El mercado nacional presenta inconvenientes para absorber una gran oferta de los productos mencionados, puesto que es informal e incipiente. La comercialización de las vainas maduras de guarango se realiza al interior de plazas, donde los principales compradores son propietarios de industrias curtiembres, comerciantes acopiadores y en menor medida, la población en general, que demanda el guarango en pequeñas cantidades, para uso doméstico o medicinal.

\section{CUERPO DEL ARTÍCULO}

La presente investigación según lo señala Arias (2006) el diseño "constituye la estrategia general que adopta el investigador para responder al problema planteado". En este caso se trabajó con un diseño transversal de campo donde los datos son recolectados en el sitio, la codificación de la información se utilizó MS-Excel y el paquete estadístico SPSS 23 para su análisis e interpretación.

Se adoptó la metodología propuesta por Méndez (2004) donde define una metodología de trabajo de investigación, que incluye los siguientes pasos:

\section{DISEÑO DE INVESTIGACIÓN}

El tipo de investigación fue descriptivo porque se describe el comportamiento de las variables de estudios y el diseño fue no experimental que se basan 
los estudios administrativos que permite construir elementos que ayudan a identificar las características de la comercialización del Guarango.

En una primera fase se realizó la revisión de información bibliográfica más representativa, tanto en formato papel y en la web la misma que es de carácter exploratorio. Con estos insumos se pudo elaborar el marco teórico y referencial.

\section{FUENTES DE INFORMACIÓN}

Durante el proceso de investigación se utilizaron dos tipos, por un lado, fuentes de información primarias y las secundarias.

- Fuentes Primarias: como fuentes primarias tenemos las encuestas realizadas a los productores de Guarango en el cantón Guano

- Fuentes Secundarias: se obtuvo información mediante la revisión de fuentes documentales relacionadas con el tema investigado, a partir de textos, documentos, artículos, páginas web, entre otros.

\section{POBLACIÓN Y MUESTRA}

La población de la investigación quedó constituida por la totalidad de los productores de Guarango en el cantón Guano que son 117 productores entre medianos y pequeños.

Se realizó un cuestionario que contó con 9 reactivos los mismos que fueron validados con la técnica de Alfa de Cronbach utilizando el paquete estadístico SPSS versión 23 el mismo que da como resultado los siguientes datos que se muestran en la tabla 1:

Tabla 1. Estadística de fiabilidad.

\begin{tabular}{cc}
\hline Alfa de Cronbach & N de elementos \\
\hline .823 & 117 \\
\hline
\end{tabular}

El resultado que se obtuvo es de 0.82 por lo cual se determina que el cuestionario es confiable.

\section{Técnicas e instrumentos de recolección de datos}

La técnica utilizada fue la Encuesta y el instrumento fue el cuestionario.

\section{Técnicas de análisis e interpretación de los re- sultados}

Para el análisis e interpretación de los Resultados se utilizó el paquete estadístico SPSS 23 y le Ms Excel.

\section{ESTRUCTURA DEL DOCUMENTO}

El presente documento se encuentra estructurado en 4 partes que es el esquema del trabajo que se muestra en la Figura 1.

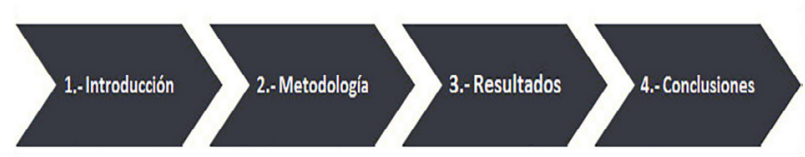

Fuente: Elaboración propia.

Figura 1. Esquema del trabajo.

La primera parte contiene una introducción y en la que se detalla el marco teórico y referencial en el cual se presentan las bases teóricas y una descripción de los antecedentes sobre el tema.

En la segunda parte se expone la metodología utilizada

En la tercera parte se exponen las derivaciones de la tabulación de la encuesta con lo que se expresa los resultados obtenidos en la investigación los mismos que se encuentra sistematizado, homogeneizado y estructurado para su fácil interpretación.

La última parte se expone las principales conclusiones y recomendaciones alcanzadas en la investigación.

\section{RESULTADOS}

En la Figura 2 se muestra las formas de comercialización del Guarango en la actualidad en el cantón Guano de la Provincia de Chimborazo Ecuador.

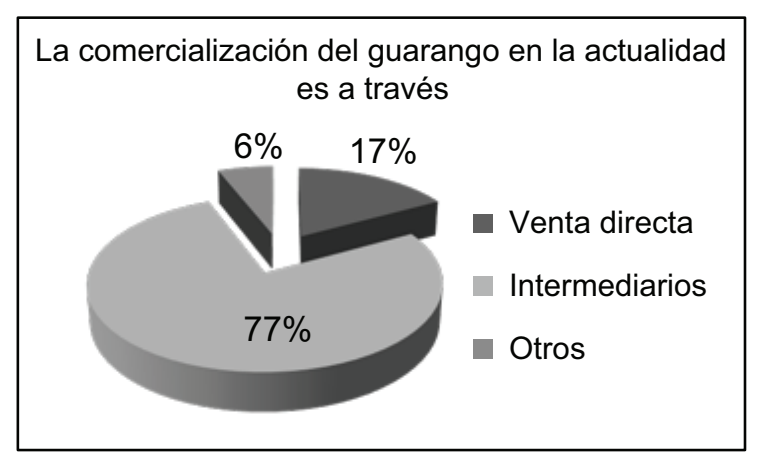

Fuente: Elaboración propia.

Figura 2. Formas de comercialización.

Del total de los productores encuestados de guarango el $17 \%$ lo comercializa directamente, el $77 \%$ a través de intermediarios y el $6 \%$ a través de otros canales de comercialización

En la Figura 3 se muestra la frecuencia de la cosecha del Guarango. 


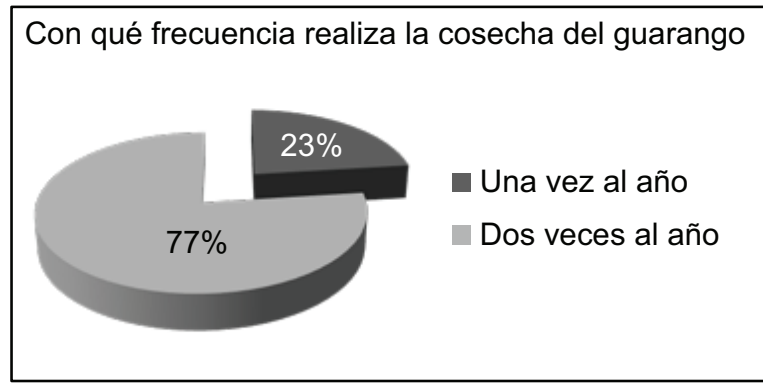

Fuente: Elaboración propia.

Figura 3. Frecuencia de cosecha.

La frecuencia de la cosecha del Guarango el $77 \%$ manifiesta que lo realizan 2 veces al año mientras que el $23 \% 1$ vez al año y la producción por árbol es de 16 a $20 \mathrm{Kg}$ por árbol, según el $77 \%$ de los encuestados el $15 \%$ cosecha de 5 a $15 \mathrm{Kg}$. y la diferencia el $8 \%$ produce más de $20 \mathrm{Kg}$ al año.

En la Figura 4 se muestra como venden los productores el Guarango en la actualidad

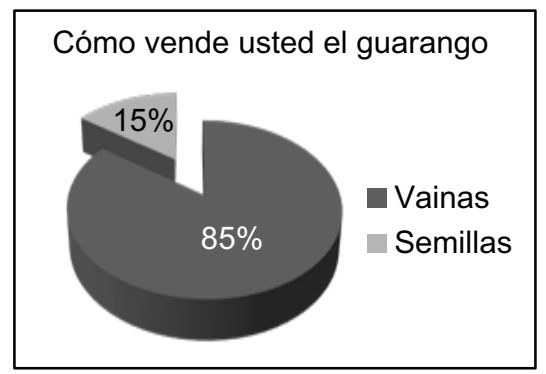

Fuente: Elaboración propia.

Figura 4. Formas de venta.

El $85 \%$ la producción del guarango la vende en vainas mientras que el $15 \%$ en semillas, el $77 \%$ conoce que el destino final de su producción de Guarango se va al extranjero tan solo el $23 \%$ conoce que su producción se queda en el país.

En la Figura 5 se muestran los niveles de beneficios que obtienen los productores del Guarango.

Los beneficios económicos que obtiene por la venta del guarango

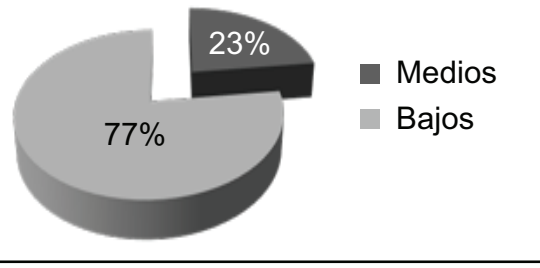

Fuente: Elaboración propia.

Figura 5. Beneficios económicos.
El $77 \%$ considera que los ingresos percibidos por la producción y comercialización del Guarango son bajos y tan solo el $23 \%$ de los mismos manifiestan que los ingresos percibidos son medios.

En la Figura 6 se muestran los niveles de beneficios que obtienen los productores del Guarango

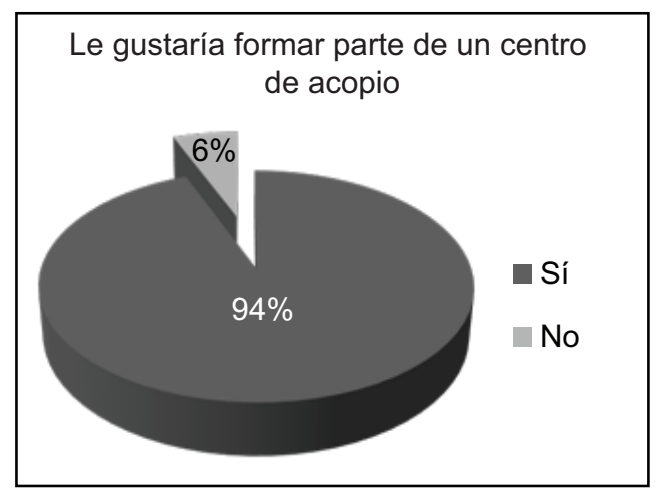

Fuente: Elaboración propia.

Figura 6. Le gustaría ser parte de un centro de acopio.

El $94 \%$ de los encuestados manifiestan que les gustaría formar parte de un centro de acopio, de estos el $77 \%$ desean un precio justo y el $17 \%$ que se pueda vender anticipadamente su producción y el $6 \%$ desean tener un contrato de exclusividad. El $100 \%$ de los encuestados consideran que la producción y comercialización del Guarango es una alternativa de ingresos para mejorar la calidad de vida de su familia.

Con todo lo anterior se establece que el mejor modelo de comercialización es crear un centro de acopio que se sugiere de esta manera como se lo demuestra en la Figura 7.

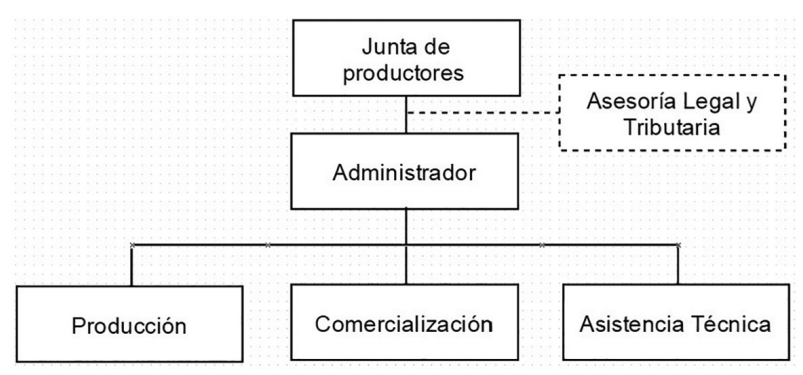

Fuente: Elaboración propia.

Figura 7. Modelo de organigrama.

La Asesoría Legal, tributaria y en todas las áreas se realizará convenios con la Universidad nacional de Chimborazo y la Escuela Superior Politécnica 
de Chimborazo que cuentan con personal especializado para que den asistencia para potencializar la producción y comercialización del Guarango.

\section{CONCLUSIONES Y RECOMENDACIONES}

- Existe un potencial crecimiento en la producción del Gurango en el cantón Guano

- El $94 \%$ de los encuestados manifiestan querer conformar un centro de acopio del Guarango en el cantón Guano

- Se debe potencializar a los productos autónomos y tradicionales andinos, el guarango tiene infinitas aplicaciones tanto en el área química como medicinal.

- Se debe de buscar que se mejoren las semillas de esta manera se busca el incremento de la producción

- Firmar convenios con la es con la Universidad Nacional de Chimborazo y Escuela Politécnica de Chimborazo, para el fortalecimiento de las distintas áreas.

\section{REFERENCIAS BIBLIOGRÁFICAS}

[1] Abbott, J. C. (1969). Problemas de la Comercialización y Medidas para Mejorarla. Santiago de Chile: Organización de las Naciones Unidas para la Agricultura y la Alimentación FAO.

[2] Alnicolsa. (2009). www.Taninos tripod.com. Lima: Tanimos tripod.

[3] Arias, F. (2006). El Proyecto de Investigación . Caracas Venezuela: Epistame C.A. /Orial Ediciones.

[4] Bednarzik, R. (2000). The role of entrepreneurship in U.S. and European job growth. Monthly Labor Review, 123(7), 3-16.

[5] Cabello, J. (2009). Monografia de la Tara. Recuperado el 21 de 12 de 2014, de www.biocomercioperu.org/adminjrecursosjcontenidosjMonografías\%20de20tara20\%final.pdf.

[6] De La Cruz , P. (2004). Aprovechamiento Integral y racional de la tara Caesalpina spinosa. Revista del Instituto de Investigación de ingeniería geológica, minera, metalurgica y geográfica, 7(14), 2-10.

[7] Editorial Oceano. (1994). Diccionario de Administración y Finanzas. México: Editorial Océano.

[8] Fernández, F., Sarramona, W., \& Tarín , P. (1977). Tecnología Didactica: Teoría y Prác- tica de la programación escolar. Barcelona: CEAC.

[9] Flores, F., \& Chavarry, L. (2005). Edad Óptima del patrón, época oportuna de injertado y producción masiva de injertos de caesalpina spinosa Tara . Cajamarca: Asociación Civil para la investigación y el desarrollo Forestal ADEFOR y Programa Andino de Fomento de Semillas Forestales FOSEFOR.

[10] García D. (Noviembre de 1975). La teoría de sistemas. Revista de Occidente(2), 52.

[11] Garnica , C., \& Maubert, C. (2009). Fundamentos de Marketing (Primera ed.). México: Prentice Hall Pearson.

[12] Garnica, C., \& Maubert, C. (2009). Fundamentos de Marketing (Primera ed.). México: Prentice Hall Pearson.

[13] Hausman , A. (2005). Innovativeness among small businesses: Theory and propositions for future research. Industrial Marketing Management, 34(8), 73-78.

[14] Hernández, S., Fernandez, C., \& Baptista, L. (2010). Metodología de la investigación. Perú: Mc. Graw Hill.

[15] Jorquera, P. (2003). Gestión de Proyectos Universitarios. El caso de una universidad Pública Chilena. Departamento de Expresión Gráfica y Proyectos de Ingeniería , 1-11.

[16] Koontz, H., Weihrich, H., \& Cannice, M. (2012). Administración una perspectiva Global (14 ed.). México: McGHraw Hill Interamericana Editores S.A. de C.V.

[17] Kotler, P. (1995). Dirección de mercadotécnia. México: Diana.

[18] Kotler, P., \& Armstrong, G. (1994). Mercadotécnia. Mexico: Edit. Prentice Hall Internacional.

[19] Kotler, P., \& Armstrong, G. (2008). Fundamentos de Marketing (Octava ed.). México: Pearson Educación.

[20] Malhotra, N. K. (2004). Investigación de mercados (4ta Edicion ed.). México: Prentice Hall.

[21] Mancero, L. (2008). La Tara (Caesalpinia spinosa) en Perú, Bolívia y Ecuador: Análisis de la cadena Productiva en la región. Programa Regional. Quito: ECOBONA-INTERCOOPERATION.

[22] Méndez, C. (2004). Metodología, Diseño y Desarrollo del Proceso de Investigación con en- 
fasis en Ciencias Empresariales (4ta Ed. ed.). México: Limusa.

[23] Mesa Holguín, M. (2012). Fundamentos de Marketing (1ra Edición ed.). Bogota: Ecoe Ediciones.

[24] Murdick, R., \& Merson, J. (1992). Sistemas de Información Administrativa (2da. ed. ed.). México: Prentice - Hill.

[25] Nicolai, A. (2007). Bases de Marketing aplicado a los agronegocios. México: Colegio de Postgraduados Campus Montecillo.
[26] Orci, E. (2007). Investigación de Mercados . México: Colegio de Posgraduados - Campus Montecillo.

[27] Villanueva, C. (2007). La tara, el oro verde de los Incas para el mundo. Lima: Universidad Agraría La Molina, Lima Perú, pp 8-11 y 26. 